\title{
Carta, novela y erotismo en don Juan Valera
}

\author{
Paloma FANCONI \\ Universidad Europea de Madrid
}

\begin{abstract}
RESUMEN
En este trabajo se analizan las ideas de don Juan Valera ante el erotismo, en la triple faceta de este escritor como crítico literario, novelista y autor de un nutrido e interesantísimo epistolario. Valera adapta su temperamento literario a estos tres géneros de escritura, que requieren actitudes distintas ante el hecho creativo, y a la vez que los entremezcla singularmente enriqueciendo sus escritos en cualquiera de los cauces señalados.
\end{abstract}

Palabras clave: novela, epistolario, crítica literaria, erotismo.

\begin{abstract}
This paper examines Juan Valera's ideas on eroticism, with a triple focus on this writer as literary critic, novelist and author of a large and interesting collection of letters. Valera's literary temperament adapts to each of these three genres of writing, which require different attitudes to the creative act; yet he also uniquely intertwines these genres to enrich his writings in any of the above forms of expression.
\end{abstract}

Keywords: novel, letters, literary criticism, eroticism.

Cuando en 1888, sale a la luz el libro de D. Urbano González Serrano Psicología del Amor, don Juan Valera publica un artículo, que después recogió en tomo en Nuevos estudios críticos el mismo año y con el mismo título: Psicología del amor. En él leemos:

Un punto hay en que estoy perfectamente de acuerdo con el Sr. González Serrano: su odio y mala voluntad al amor vulgarmente llamado platónico. Es sofistería que, siendo el hombre y la mujer compuesto de alma y cuerpo, y mediando la diferencia de sexo y la inclinación natural y poderosa que de ella nace, prescindamos del cuerpo y nos amemos sólo con el alma. Al pretender, que así lo hacemos, ya que no queramos engañar a otros, nos queremos engañar a nosotros mismos. Para que un hombre ame a una mujer o una mujer a un hombre solo con el alma, es menester que el ser amado haya muerto, o que el que ama esté descabalado. De lo contrario hay en 
este amor, aunque fuente de riquísima poesía, no sé qué de alambicado, falso y artificioso. ${ }^{1}$

Es idea que encontramos también en Genio y Figura, publicada nueve años después, en 1897, en la que pone en boca de la protagonista las siguientes palabras:

Yo no niego ni afirmo la existencia de lo que llaman amor platónico; pero, si existe, hallo en él, mientras vivimos esta vida mortal y tenemos alma en el cuerpo, y cuando son los que se aman mujer y hombre, un no sé qué de incompleto y aun de monstruoso. ${ }^{2}$

Como vemos, el autor cordobés defiende que el platonismo es apto para una expresión poética que puede ser riquísima, pero que según va expresando más adelante en el referido texto crítico, es fruto de una serie de espíritus generosos que ante el trato vejatorio del que han sido objeto en determinadas épocas las mujeres, se alzan y hacen de ella un ser elevado y angelical, pero no real, o más que irreal, podríamos decir inverosímil.

En el mundo de la fantasía, que es el mundo de la novela, debemos admitir, no ya como verosímiles, sino como verdaderos, todos los legítimos engendros de la fantasía. El criterio de la verosimilitud es el que decide sobre la legitimidad de esos engendros sometidos en su nacimiento, en su desarrollo y vida a ciertas leyes de conveniencia y de lógica. ${ }^{3}$

Es una idea que mantendrá siempre y que seguirá defendiendo a lo largo de su vida en las diferentes manifestaciones de su pensamiento crítico literario.

Dentro de esta idea de la verosimilitud fantasiosa, o más bien como base de ella, debemos tener en cuenta su principio teórico de que la novela es poesía, es una manera de poesía. El concepto de lo poético y la idea de la ficción, son rasgos que caracterizarán su quehacer literario, que matizará, personalísimamente, con ese profundo sesgo clásico que le caracteriza y le singulariza respecto a sus coetáneos novelistas del realismo.

Llamo a la novela poesía, aunque las novelas, por lo general, se escriben en prosa, porque ni son historias, ni Ciencia, ni Filosofía, y, aunque no estén en verso, no dejan de ser parto de la imaginación poética [...] Poesía, pues, son las novelas, aunque poesía libre de metro y con mayor licencia para descender de lo sublime y noble a lo vulgar y pedestre que lo que estrictamente se llama poesía. ${ }^{4}$

${ }^{1}$ Cfr., J. Valera (1888). p. 378.

2 J. Valera, (1975). pp. 227-228.

${ }^{3}$ J. Valera, (1996). p. 78.

4 J. Valera, (1996). P. 75. 
Lo vulgar y pedestre no es nunca en él lo obsceno y desagradable. Valera habla de lo ordinario y lo pedestre en el sentido de lo común y cotidiano: como de aquello que es propio del vulgo, de la gente corriente. Sus personajes, que son normalmente "gente común" -y si no lo son, y esto es importante, Valera hace que lo parezcan- , pocas veces van acompañados de lo soez o de lo feo.

"La diferencia que media entre la Historia y la poesía está en que la Historia pinta las cosas como son, y la poesía como debieran ser"”

Sus Apuntes para el nuevo arte de hacer novelas están llenos de apreciaciones de este tipo, que en lo referente a la expresión de las relaciones sexuales, se concretan en la necesidad de delicadeza y buen decir. Comentando cómo es tratado este asunto por los naturalistas señala, por ejemplo:

“...si una mujer se conserva relativamente casta, es porque no tiene sangre en las venas porque es linfática; pero si tiene sangre y buena salud, no hay más sino que, como mil otras, y como la heroína de la novela, se entrega, por curiosidad carnal, a los catorce años, al primer hombre que se le ofrece y luego se da a muchos otros a diestra y siniestra en los rincones de las callejuelas...",

Y, especialmente, respecto a las palabras malsonantes:

"Lo cierto es que los naturalistas abusan de las palabras sucias, creyendo que así dan más verdad y energía al habla de sus personajes."

Para Valera la expresión novelesca del erotismo ha de ser, pues, siempre adecuada y decorosa, precisamente por ese clasicismo que domina su literatura, muy especialmente, por el carácter poético del que dota al género. Pintar las cosas como deben ser, no con afán de enseñar, sino de deleitar.

Son muchas las ocasiones en que se queja de las novelas moralizantes, y defiende la necesidad del deleite como fin fundamental de tales obras. Si al lector se le pone siempre ante crudas realidades, para él exageradas y casi grotescas, en vez de deleitarse y pasar un buen rato, sufrirá con los personajes y, ante las escatológicas situaciones que la moda naturalista incluye en sus relatos, sentirá asco y repugnancia.

En este sentido es especialmente cómica la parte de sus Apuntes...en que comenta que, tras haber leído Germinal, a él, que en ese momento está padeciendo los rigores del invierno belga, le da cargo de conciencia defenderse de las inclemencias del tiempo con estufas de carbón.

Volviendo a su Psicología del amor, Valera sostiene, comentando los famosos versos iniciales del Libro del Arcipreste de Hita:

\footnotetext{
${ }^{5}$ J. Valera, (1996) p. 76.

${ }^{6}$ J. Valera, (1996) p. 142.

${ }^{7}$ J. Valera, (1996), pp. 158-59.
} 
Y para satisfacción del otro apetito, el hombre civilizado, por artes cosméticas e indumentarias, y por medio del aseo y de linimentos y afeites, y valiéndose además de la higiene y de la gimnástica, realzará la hermosura de la mujer y su gallardía, exornándolo todo con dijes y brinquillos, y con vestiduras que en parte pongan de relieve, y que en parte velen o encubran todo aquello que el misterio pueda hacer deseable.

Así pues, los cuidados, el cortejo, la preparación psicológica para la fusión corporal son, para nuestro autor, fundamentales. No por moralidad, ni mucho menos por ñoñería, como veremos más adelante, sino porque lo lleva en sí el género novela. La sexualidad no es para él, en su literatura, una mera manifestación del apetito. El hombre civilizado sofistica más las cosas, y desde luego Valera es un partidario de la civilización. Su conocimiento de la lengua helena fue tan perfecto que llevó a cabo brillantemente traducción al castellano de la novela de Longo, Dafnis y Cloe, aunque personalizándola al cambiar el sexo de uno de los personajes secundarios para evitar que en el texto se cometiera un acto de homosexualidad. Su oposición al contacto erótico entre personas del mismo sexo, lo manifestó expresamente en la obrita que venimos citando a tenor del comentario del libro de González Serrano:

El desdén, el desprecio y la domesticidad servil con que en Oriente y en la antigua Grecia fue mirada la mujer; las diatribas que filósofos adustos lanzaron contra ella, y el errado convencimiento de que es ser muy inferior al hombre, han de haber contribuido en gran manera al monstruoso amor entre personas del mismo sexo ${ }^{9}$

Valera, en sus novelas, se recrea en los preparativos eróticos y nunca cuenta detalladamente las consumaciones.

En esa preparación psicológica es, no cabe duda, un escritor genial. Pero además, enlazando con las palabras de consideración hacia las mujeres que hemos citado, sus heroínas jóvenes son, en muchas ocasiones, además de bellas, astutas y sensuales. El propio autor nos explica la personalidad de algunas de ellas y sus comportamientos sexuales en Pasarse de listo, publicada dos años después de Pepita Jiménez:

No negaré, en cambio, que doña Blanca había pecado, y que la ferocidad de su penitencia era peor que el pecado mismo: que Pepita Jiménez fue demasiado coqueta y más apasionada de lo razonable, y que una vez enamorada no sabía contenerse, y se disparaba como una pistola al pelo; que María, la inmortal amiga, se abandonó a su pasión como si no hubiese tenido libre albedrío, como si hubiese sido impulsada por una fuerza irresistible; que Constancia era interesada, calculadora y caprichosa, y que Rosita no reconocía más ley divina o humana que la de su antojo; pero en todas estas mujeres (nadie sostendrá lo contrario) se advierten, en medio de sus mayores extravíos, tal anhelo de infinito amor, tan dulce ternura y tan fervoroso ahínco de hacer el papel de salvadoras y de redentoras, de proporcionar la bienaventuranza para

\footnotetext{
${ }^{8}$ J. Valera, (1888), p. 358.

${ }^{9}$ J. Valera, (1888), p. 365
} 
el hombre querido, aún a costa de su propia condenación, que las perdonamos sin esfuerzo y nos parecen simpáticas. ${ }^{10}$

Por su carácter poético, pero también por su adecuación a la realidad, a su concepto del ser humano y su modo de amar, (lo hemos visto al inicio de este trabajo: el hombre es alma y cuerpo y por eso no existe el amor platónico) tampoco existe -en sus novelas- la mera carnalidad, y si existe, siempre sale malparado quien la ejerce.

En las novelas que componen lo que se ha llamado la segunda época de Valera, este sentido redentor de sus protagonistas femeninos que señalaba en Pasarse de listo, se acentúa, y en este aspecto pocas heroínas más sensuales, más seguras de sus encantos y más "redentoras" de varones hay en las novelas de don Juan Valera, que la Rafaela de Genio y figura.

Rafaela es el personaje femenino al que más estima el autor. Es cierto que con frecuencia señala expresamente sus defectos. La califica a menudo y no siempre positivamente, pero el autor parece tener en alta estima a esta señora, la última en el elenco de sus apasionantes heroínas. Censura algunos rasgos de su carácter, pero la quiere tal y como es, y hace de ella una mujer de alta dignidad a su manera. En una carta al Doctor Thebussem, Mariano Pardo de Figueroa, del 17 de marzo del 97, Valera dirá de su protagonista:

Mi querido Dr Thebussem: con mucho contento recibí ayer la carta de Vd. del 13, lisonjeándome no poco el elogio y la defensa que hace $\mathrm{Vd}$. de la pobrecita Rafaela, contra la cual se han desatado en improperios algunos críticos pudibundos. Mi intento fue pintar a esa mujer que, nacida en el fango y el vicio de las calles, se va elevando poco a poco y comprendido toda la belleza moral que en la mujer cabe. Si hay una de estas bellezas que no se realiza nunca es porque la vergüenza perdida con dificultad se recobra. Su mocedad, sus bríos y el amor a su madre, unido todo a la fe religiosa, sostienen a Rafaela, que, a pesar de sus frecuentes caídas, sueña con amor puro, exclusivo y único. ${ }^{11}$

Rafaela es apodada La Generosa, y efectivamente regala sus favores sexuales a diversos hombres, a los cuales educa, suaviza o refina, como en el caso de su marido. En Rafaela no hay vulgaridad. No se enamora más que de Juan Maury, el que será padre de su hija, pero se sabe bella y atractivísima, en ello se complace, y en ocasiones, (como cuando se une al joven uruguayo de 18 años cuando ella, ya viuda y en la treintena decide regresar a Europa), confiesa que le produce más placer el que es capaz de proporcionarle a su amante que el que obtiene por su propio deleite sexual.

Este hábito de Rafaela a los placeres de la carne es una mezcla de vanidad y de compasión, de costumbre y de generosidad. Tan es así que, en las "Confidencias" finales que le dirige al vizconde, al relatar la cita que decide tener con el barón para

${ }^{10}$ J. Valera, (1883), pp. 188-189.

${ }^{11}$ Juan Valera, (2002-2009). Siempre que cito las cartas de Valera lo hago por esta edición de su Epistolario. 
consumar el deseo de éste, Rafaela siente lástima ante la impotencia sexual de su pareja y la delicada reacción de la experta amante no puede ser más suave y misericordiosa.

Pues bien, esta sutileza teórica y práctica que sostiene Valera para y en las novelas, en lo que a las relaciones sexuales se refiere, y que defiende tan vehementemente en sus obras de teoría y crítica literaria, desaparece en su interesantísimo y extenso Epistolario.

Para afrontar la lectura de sus cartas hemos de tener en cuenta la sólida formación clásica de Valera a la que ya hemos aludido y que tan constantemente ha sido señalada, porque en sus cartas va dejando a lo largo de su existencia notable cuenta de sus aventuras e ideas eróticas, y como buen humanista conocía la importancia de las epístolas o cartas familiares que, casi en un concepto de género literario, desarrollaron tanto muchos grandes escritores del XV y XVI, con los que comparte, lógicamente, su conocimiento del mundo clásico.

Recordemos que en las palabras preliminares que Fray Antonio de Guevara dirige al lector al frente de sus Epistolas Familiares señalaba: "Viendo, pues, que unos me las hurtaban, otros las imprimían y otros por suyas las publicaban acordé de las repasar y con todos comunicar." Es decir decidió que pasaran de carta privada a cartas públicas.

Es el mismo proceso que acontece con las Cartas desde Rusia de Valera, aunque fue, en un principio, contrario a la voluntad del autor. Es anómalo el paso de la carta familiar a artículo epistolar sin modificación por parte del autor. Cuando él marcha a Rusia con el Duque de Osuna como miembro de la Legación Española, comienza una correspondencia con su superior y amigo, Leopoldo Augusto de Cueto, que era Subsecretario de Estado, comentándole el viaje. Las cartas se difunden en su versión auténtica en la Secretaría de Estado, en el Casino de Madrid y hasta en Palacio. Pero Cueto da un paso más: las publica en $L a$ España, denominándolas Cartas familiares $^{12}$. El texto publicado en La España pierde gran parte de su gracia inicial, aunque gane en decencia y discreción. Cueto adapta los contenidos: los comentarios acerca del país, las críticas sobre sus compañeros de expedición, y, por supuesto, todas las alusiones sexuales. Lo verdaderamente importante es que Valera, al enterarse de que sus cartas están pasando al dominio público, altera el estilo: aminora la crítica y la ironía, aunque sin llegar a los extremos de Cueto.

Este proceso de publicación de cartas privadas, lo padecerá Valera de nuevo en los años finales de su vida, y en carta a Thebussem de 20 de enero del 98 se queja:

Mi querido Dr Thebussem: el Sr. Gómez Carrillo y como él todos los americanos son unos seres insufribles, dañinos y muy poco de fiar. Ya es la segunda o tercera vez que me publican cartas que no son para la publicidad y que yo escribo desenfadadamente, provocado por ellos. Será menester parapetarse en la grosería y no contestarles nunca, o bien contestarles pesando y midiendo cada palabra, no como si se dirigiese uno a

${ }^{12}$ J. Serrano Asenjo, (1995). 
alguien en particular, sino como si a todo el público de ambos hemisferios se dirigiese.

Otras cartas que escribirá -Las cartas americanas- serán sin embargo concebidas como críticas literarias en forma epistolar, destinadas desde el comienzo a ser publicadas en prensa.

Acerca de este proceso de publicación o no de sus cartas personales y el cambio de estilo y contenido que ello podría suponer, se pronuncia Valera expresamente denominándolas "familiares", en una escrita al Dr. Thebussem el 27 de mayo de 1899:

Con respecto a lo que Vd. me aconseja de escribir Memorias o Cartas sobre sucesos de mi tiempo, le diré que esto es una cosa y otra que yo, en cartas familiares e íntimas, como las que envío a Vd. en el seno de la confianza y con el debido sigilo, cuente anécdotas y lances cómicos sobre las personas que en mi ya larga vida he conocido y tratado. Si esas cartas mías fueran verdaderamente interesantes y amenas, acaso podrían publicarse; pero no ahora, sino dentro de cuarenta o cincuenta años. Quien las publicase antes, me haría, en mi sentir, muy flaco servicio. Lo mejor es que no se publiquen nunca. Y yo aseguro a Vd. que si llegase a persuadirme de que mis cartas familiares pudieran ser publicadas, y si tal idea apareciese ante mi espíritu cada vez que voy a escribir una carta, todo el chiste y todo el primor que esta carta pudiera tener desaparecería por completo, porque no tendría yo el abandono, la franqueza y la casi licenciosa libertad que tengo al escribirla ahora.

Por otro lado, su interés cultural por los epistolarios le llevó en su estancia en San Petersburgo a ir copiando y enviando a Cueto unas que encontró de Felipe II en la Biblioteca Imperial de la ciudad del Neva. Valera, autor epistolar es asimismo transcriptor epistolar de las del monarca español para que los eruditos puedan estudiarlas en España.

Lógicamente, como tuvo que pasar mucho tiempo fuera de su país, para mantener el contacto con sus compatriotas hubo que escribir muchas epístolas, pero es que además, lo que es evidente es que a Valera le gusta escribir cartas y le gusta y sabe escribirlas bien. No en vano su primera y gran novela es epistolar.

Por sus cartas sabemos mucho de sus ideas sobre los países en que vivió, de sus opiniones sobre las obras que leyó, sobre los trabajos y encomiendas que realizó, y sobre los hombres y...las mujeres que trató. Y los sabemos con tanto detalle, que podemos decir, basándonos en ellas, que don Juan fue un hombre experto en el amor. Atractivo, interesante, culto, noble, refinado, y apasionado por las mujeres desde su primera juventud.

Ya en la primera carta que figura en la edición del profesor Romero Tobar, dirigida a su padre cuando el autor es todavía estudiante en Madrid en el año 47, cuenta una de sus posibles conquistas amorosas con una viuda vecina suya. En carta del 21 de enero del mismo año relata a su propia madre su affaire con una tal Paulina, condesa de C...Divertidas y muy nutridas de información erótica son muchas de las 
que escribe desde Río de Janeiro, como la que dirige a Serafín Estébanez Calderón el 1 de septiembre de 1853, en la que, por ejemplo, leemos:

Mucho me atemoriza que el calor y la humedad disminuyan aquí el entendimiento de los europeos; y más aún no dándoles compensación alguna como les dan a los brasileños, a los que se cuenta que les hacen crecer desmesuradamente no ya las alforjas, sino el instrumento mismo; por cuya razón no hay aquí europeo que satisfaga a las señoras, y cuyas pertenencias no pasen por una parvedad microscópica. A mí al menos me ha sucedido así con cuantas mujeres he conocido bíblicamente; y Juanita, aunque francesa, acostumbrada ya a lo desaforado y giganteo, me llama son petiti ioseau, y no el de San Viril.

Y en una fechada el 28 de octubre de 1855, descendiendo a otra escala social, comenta al mismo destinatario desde Madrid:

Las putas están desesperadas con el cólera, pues, por sus respetos, pocos son los que en estas circunstancias se atreven a pecar. Ayer estuve en casa de Violante, que está también algo alicaída con la falta de parroquianos. Me recibió no obstante, o acaso por lo mismo de que los parroquianos andan ahora por las nubes, con notables extremos de ternura; y me enseñó las tetas y las pantorrillas para demostrarme que se hallan tan frescas, duras y sonrosadas como yo las dejé antes de irme a Dresde No me enseñó más porque yo comencé a asustarme, y ella hubo de conocerlo.

Muchas expresiones me dio para Vd. y para su amigote D. Próspero. Mingnonnete, aquella putilla francesa que acaso Vd se haya tirado alguna vez, que yo me he tirado tantas veces, y que era a no dudarlo la que hacía mejor en Madrid cuanto hay que hacer in re venérea, murió de cólera tres días ha; y la amaban tan entrañablemente muchas de sus compañeras, que no puede Vd. imaginarse cuánto la han llorado, y cuán lujoso entierro le han hecho. Iban en él muchos carruajes, y un carro fúnebre de los más pomposos y grandes."

Pero no todas las aventuras amorosas de Valera fueron de esta guisa. El propio autor confiesa haber estado enamorado en su juventud de Gertrudis Gómez de Avellaneda (carta a Luis Ramírez de las Casas-Deza, Madrid, 5 de enero de 1863). Conocido es su romance con La Muerta, Lucía Palladi, dama rumana casada y mayor que él, a la que conoció en los círculos aristocráticos italianos y por la que mantuvo toda la vida particular admiración y afecto. Pero especialmente interesante, en su epistolario, es el episodio amoroso con Magdalena Brohan.

Magdalena Brohan era una famosa actriz, que entonces actuaba en la ciudad rusa. Muchos admiradores de la alta sociedad la cortejaban, entre ellos el Duque de Osuna, entonces jefe de la legación española en aquel país. La Brohan, que estaba separada de su marido, tenía un amante en París, y en la carta a Leopoldo Augusto Cueto desde San Petersburgo el 13 de abril de 1857, Valera confiesa:

Yo me creía ya un filósofo curtido y parapetado contra el amor, pero me he llevado un chasco solemne $[\ldots]$ No pienso más que en este amor y me parece que voy a 
volverme loco. Ríase usted, que harto lo merezco. No tengo más consuelo que hacer de todo esto una novela...

Es el proceso genérico inverso a la creación de Pepita Jiménez. Si esta es una novela epistolar, ahora estamos ante unas epístolas novelescas en las que vemos aunado al hombre-protagonista del relato, al creador-autor de la carta-novela y al crítico, que hace la definición genérica del episodio como "novela en carta". Conocemos sobradamente la maestría con la que Valera se sirve de la epístola en sus novelas. No sólo en Pepita Jiménez. El recurso de la carta es frecuente en sus narraciones, aunque no constituya el esqueleto de todas sus obras de ficción, como sí hizo en Pepita. En esta fusión de ambos géneros hay pocas plumas que igualen su destreza creativa. Lo que sí debemos señalar es que la publicación de su primera novela es muy posterior a estas primeras cartas de que estamos hablando, y en concreto a esta denominada por él mismo carta-novela concretamente, redactada en abril del año 57. Parece como si en cierto modo su epistolario personal fuera un ensayo para la que luego será una de sus técnicas narrativas más logradas. En realidad Valera en sucesivas cartas va narrando a Cueto su historia de amor, una historia de amor que alcanza la categoría de novela, como hiciera Luis de Vargas con su tío el Deán. De hecho, su historia de amor con la Brohan ocupa varias misivas alternas, pero comienza en la dirigida a Leopoldo Augusto Cueto que estamos comentando, y donde aparece caracterizada como novela la historia de amor que procede a contarle. Tras relatar los primeros encuentros entre ambos, con frecuentes alusiones literarias, encontramos fragmentos como el que sigue:

En fin, estábamos solos, y ella en la cama, más bonita que nunca. Nos miramos de nuevo los ojos, nos acercamos, se encendieron nuestros ojos y llegué a darle un beso en la frente. Se incomodó o fingió incomodarse, y me rechazó. A todo esto no se había hablado ni una palabra de amores. Entonces, sentado a la cabecera, y casi inclinado sobre la cama, me puse a mirarla en silencio y muy fijamente, y a ella se le adormecieron los ojos, y se le humedecieron, y me dijo que la magnetizaba y que se iba a dormir; que si sabría yo desmagnetizarla luego. [...] Obedecí humildemente, y dejé de mirarla; me eché sobre el sillón, me puse a suspirar como enamorado y a callar como en misa. Magdalena se incorporó entonces y me miró a su vez, con ojos tan cariñosos y provocativos, que me levantó en peso del sillón, y diciéndola, "te amo", me eché sobre ella, y la besé y la estrujé y la mordí, como si tuviese el diablo en mi cuerpo. Y ella no se resistió, sino que me estrechó en sus brazos, y unió y apretó su boca a la mía, y me mordió la lengua y el pescuezo, y me besó mil veces los ojos, y me acarició y enredó el pelo con sus lindas manos, diciendo que tenía reflejos azules y que estaba enamorada de mi pelo; y me quería poner los besos en el alma, según lo íntima y estrechamente que me los ponía dentro de la boca, y nos respiramos el aliento, sorbiendo para dentro muy unidos, como si quisiéramos fundirnos y unimismarnos. En fin, fue una locura de amor que duró hasta las dos de la noche, desde las nueve. Pero nunca consintió ella, por más esfuerzos que hice, en hacerme venturoso del todo. 
Es una carta familiar, en la que refiere su enamoramiento e inicial despedida de la actriz francesa. Por el estilo, los contenidos, los personajes que van apareciendo y la manera de contar lo acontecido con la Brohan esos días, los anteriores a Semana Santa, -incluida la ironía continua- se puede perfectamente calificar de epístola literaria más que en el de epístola familiar, aunque las confidencias vertidas sean de lo más personales. El mismo Valera se despide de Cueto diciendo:

Adiós. Esta carta no debe formar parte de la colección de mis cartas de Rusia. Esta carta está fechada en el país $d u$ tendre.

Según cuenta Valera, encuentros de este tipo se sucedieron una y otra noche, pero en palabras del autor "a pesar de mis arremetidas siempre me he quedado a media miel"

Estas incompletas citas amorosas finalizan mal. Valera se enerva, y pierde los papeles. Así lo cuenta en carta a Cueto el 23 de abril del 57:

Mas, como a todo esto me besaba la cabeza, y jugaba con mis cabellos, y ponía sus labios en los míos, y me los pasaba por los párpados, que yo cerraba, no pude contenerme dentro de los términos razonables y decorosos, y la di la tarquinada más brusca y feroz que he dado en toda mi vida. Pero sabido es que nada hay más imposible que forzar una mujer.

\section{No hubo mujer forzada}

Desde Elena la robada,

como dice el villano de Tirso. Mi ataque desaforado no sirvió sino de ponerla furiosa, de hacerla llorar más, de acusarme de brutal y de no sé cuántas otras cosas, y de tener que largarme de su casa, aunque perdonado y absuelto, bastante fríamente.

El 29 de abril escribe de nuevo a Cueto:

Debiera tener por excusado el decir a usted, porque ya lo sospechará, que he vuelto, pro vez tercera, a caer en las redes de la Brohan. Los mismos excesos y la misma imposibilidad de llegar al último extremo de los amores.

El 6 de mayo remite otra al mismo, enumerándole algunas visitas que hace a otras damas con el intento -fallido- de olvidar a la Brohan, y hace de nuevo referencia al género híbrido de carta novelesca al que venimos refiriéndonos:

Hoy tenía yo asunto para escribir una carta novelesca de cinco o seis pliegos contando mis correrías con Lapujin, que han sido muchas y curiosas, mas el humor, el tiempo y las fuerzas me faltan. Estoy muy melancólico y nada floreciente de salud. La burla de los calzoncillos me ha cogido de medio a medio, como si hubiese yo escupido contra el cielo.

La última alusión que hace a la Brohan en su epistolario es el 23 de junio de 57 desde París. Fueron sólo unos meses, pero la intensidad emocional con la que vivió Valera este episodio produjo en su pluma unas cartas autobiográficas que hemos ido referenciando que, por lo vigoroso del estilo y lo íntimo de las confesiones tienen alto interés. 
No fue ésta la única experiencia sexual que tuvo Valera en San Petersburgo. Dos meses antes de sus amores con la Broham, en carta 26 de febrero del 57, escribía a Cueto:

He descubierto establecimientos eróticos mejores que los que me eran antes conocidos. Hay uno donde suena un órgano durante el coito, y le celebra uno con toda pompa y majestad al son de la música; y hay asimismo casas de baños con muchachas bonitas que lavan y pulen al que se baña y se entregan con él a la fornicación anfibia. Todo esto dará a usted una alta idea de la civilización de este pueblo, que conoce y ejerce todos los métodos de que habla Mirabeau en su Erotica biblion. Fuerza es confesar, con todo, que aún faltan aquí muchos perfiles, y que las ninfas rusas aun no parissianum expolito more penem lambunt, o si se prestan a este acto es con dificultad y repugnancia o movidas de un exceso de ternura hacia el favorecido y dichoso mortal

En contraste con esa apasionada e incompleta historia amorosa que se refleja en su epistolario, destaca el noviazgo oficial que mantiene con otra Magdalena, Magdalena Burgos, cuya primera aparición en la obra es en la carta que dirige a Gumersindo Laverde el 30 de agosto del 63 y de la cual refiere a Francisco Moreno Ruiz el 19 de diciembre de 1863 :

Esto, dicho por usted, con travesura y discreción, a alguien que a papá B[urgos] se lo transmita de un modo natural, sencillo y no ocasionado a sospecha de que está concertado, podrá servir a uno de dos fines: o que se disguste papá B[urgos] y rompa conmigo amistosamente; o a que, si no quiere romper, se decida a dar una dote decente a su hija $[\ldots]$

Ya usted comprenderá que yo no quiero el dinero para mí, ¿qué es un millón de pesetas en último resultado? Pero si me caso, por lo mismo que ella es una señorita de lugar, tendré que adobarla, pulirla, vestirla y perfumarla, y hasta ponerle maestro de gramática y hacerle aprender algo de ortografía, de historia y de lo que saben las personas de mundo, para que no suelte papas. La chica tiene mucho entendimiento, pero está cerril. En suma: con algún dinero se puede encubrir o remediar todo esto; pero si papa $\mathrm{B}$ [urgos] no da nada más que la mano de su hija, ya comprenderá usted que yo no habré hecho un viaje a la India.

El acuerdo sobre la dote se dilata. Ya había escrito Valera a José Freuller el 1 de enero del 64: "Muchas putas viejas amigas mías han tenido que reír en grande con esta novia pastoril y campestre que me he echado", y el 27 del mismo mes y año confiesa al mismo amigo:

Cuando contraje aquel compromiso estaba yo desengañado de esta vida cortesana y deseoso de retirarme a buen vivir. Entonces, esto es, durante cuatro o seis meses, me hubiera yo casado con la ninfa lucentina, por poco que su padre le diese. Ahora, si sólo dependiera de mí, no me casaría por nada del mundo. El padre me carga y toda la familia me carga. 
Efectivamente Valera no consumó el compromiso, y se casará en París el 5 de diciembre de 1867 con Dolores Delavart a quien le dirige la primera carta el 11 de octubre del mismo año. El 13 de octubre escribe a Laverde contándole sus intenciones de boda y la necesidad de romper "otros amores más profanos" y declara:

La novia de París me conviene y me agrada mucho. Es modesta, juiciosa, discreta y bien educada: pero me duele el desengaño y la mala partida de que voy a hacer blanco a la otra.

Muchos años después, en el 96, cuando tiene 73 años, a la par que escribe Genio y figura, su novela más erótica, como el mismo autor declara en carta del 20 de enero del 97 -y que fue tachada de inmoral por parte de la crítica- Valera está preparando, junto al Dr. Thebussem, sus Cuentos y chascarrillos, cuyo primer tomo, en julio del 96, ya se estaba vendiendo con gran éxito y que fue, también, calificado de indecente. El novelista se defiende de estas acusaciones, en carta a su colaborador el 5 de septiembre del 96:

De las cartas que en La Unión Católica me dirige Francisco Estepa, he leído una. He tenido curiosidad de leer otras y no he podido hasta ahora haberlas a la mano. Diga lo que diga el de Estepa, yo no pienso contestarle palabra. Su deseo es ese y por lo mismo no me conviene acceder a su deseo. Lo que yo he leído, además, no merece contestación. Todas las indecencias y todas las porquerías que hay en nuestros cuentos y chascarrillos son pecata minuta comparadas con las de Aristófanes, Luciano, Apuleyo, Horacio, Catulo, Petronio, Maquiavelo, Boccaccio, Ariosoto, el autor de La Celestina, Rabelais, Voltaire, Cervantes, Quevedo y, en fin, la Biblia.

En el 99 el ya anciano Valera, lleno de achaques y ciego, mantiene su sentido del humor y escribe a Thebussem:

Lo que es conveniente y deseable es que cada cual se regenere individualmente como pueda y hasta donde pueda. Ojalá que Vd. lo consiga con esas aguas de Marmolejo que va a tomar pronto. Yo también me complacería en extremo de conseguirlo para mí, ya con aguas medicinales, ya por otros medios, aunque fuesen diabólicos y de hechicería, con tal de recobrar la vista, desechar la flojedad de las piernas y del estómago, adquirir frescura y serena fecundidad para el ingenio, y para otras cosas perfecta rigidez y tensión, tres o cuatro veces a la semana. Esta sí que sería regeneración exquisita y deliciosa.

De los deseos que manifiesta en esta carta, uno, sin duda, se vio cumplido, porque en ese mismo año publica Morsamor, un verdadero deleite para los lectores, su novela más diferente, la más imaginativa y, para muchos, la mejor.

Valera había manifestado en repetidas ocasiones -lo hemos visto- su recelo ante la posible publicación de sus cartas familiares, pero con el tiempo han salido a la luz completas. Efectivamente, esa licenciosa libertad a la que hacía referencia, es precisamente lo que llama la atención en escritor tan afianzado en la conveniencia del bien decir en su crítica literaria como recatado y pulcro en su creación novelística. 
Una es la postura de Valera en el plano teórico y creativo y muy otra la del hombre que confidencia con sus amigos personales. Pero -notémoslo bien- esa diferencia la había resaltado el propio escritor, consciente de la posibilidad de que sus "libertades licenciosas" salieran a la luz algún día. A este gran conocedor y estudioso de la Literatura no se le pasó esta posibilidad por alto. Él mismo nos ha dado la clave. Sólo un crítico tan sabio y tan perspicaz podía tener esta perspectiva sobre sí mismo.

Por eso, el día que murió don Juan Valera, dice Adolfo Bonilla y San Martín en el decir que le escribió en septiembre de 1905, que Iris, la radiante mensajera de alas cerúleas, fue a decirle a Carón para que se lo comunicara a sus dueños:

...en breve llegará a esta mansión el anciano poeta de cabellos de plata, honra de Hesperia. Esmorece ahora en la tierra donde el Sol se pone" y que Tiresias, cuando fue a recibirle a las puertas del Hades, le consoló de esta manera:

No te duelas por haber descendido a esta siniestra morada. El Hado, superior a la voluntad de los dioses mismos, te señala otro destino. En breve irás al Empíreo, lugar de los Inmortales. Allí descenderás por el camino de la sublime albura que los dioses siguen, y cuando llegues a su santuario de mármol donde tu trono se halla, verás al Padre Supremo, de terrible cabellera y cetro de marfil, que sobre el Universo manda y al que todas las cosas obedecen

"Sin embargo -continúa el autor del texto, lo mismo que podemos decir nosotroslloro aquí, no la suerte del poeta ciego de cabellos de plata, que asciende al Empíreo por la vía de la sublime altura de los Inmortales, sino la mía propia, porque sé que al cerrar para siempre los ojos, cuando Carón me traslade al terrible Hades, no he de encontrar allí para dulcificar mi angustia la faz serena, ni la palabra insinuante de mi maestro el viejo poeta de Hesperia"

Pero nos quedan sus poemas, sus juicios, sus novelas y...sus cartas.

\section{OBRAS CITADAS}

SERRANO ASENJO, J., "Las cartas rusas de Valera de La España, entre la censura y el eufemismo", en Juan Valera, creación y crítica. Ed. Cristobal Cuevas, Málaga, 1995, pp. 213-223

VALERA, Juan, Obras de D. Juan Valera. Nuevos estudios críticos, Madrid, Imprenta y fundición de M. Tello. Impresor de Cámara de S.M., D. Evaristo 8, 1888.

VALERA, Juan, Genio y figura, edición de Cyrus de Coster, Madrid, Cátedra, 1975. VALERA, Juan, De la naturaleza y carácter de la novela, en Juan Valera: el arte de la novela. Prólogo y selección de Adolfo Sotelo Vázquez, Barcelona, Lumen, 1996.

VALERA, Juan, Pasarse de listo, Sevilla, Francisco Álvarez y C editores, 1883.

VALERA, Juan, Correspondencia, edición de Leonardo Romero Tobar (Dirección) $\mathrm{M}^{\mathrm{a}}$ Ángeles Ezama Gil y Enrique Serrano Asenjo, Madrid, Castalia, Nueva Biblioteca de erudición y crítica, 8 volúmenes, 2002-2009. 